\title{
Comparing the Hemodynamic Effects of Nebulized Dexmedetomidine and Nebulized Lidocaine in Children undergoing Fiberoptic Bronchoscopy
}

\author{
Amir Shafa $^{1}$ (D), Mohammadreza Habibzadeh1 ${ }^{(D)}$, Hamidreza Shetabi ${ }^{1 *}$, Ali Aghil ${ }^{1}$ \\ 1. Dept. of Anesthesiology, Faculty of Medicine, Isfahan University of Medical Sciences, Isfahan, Iran
}

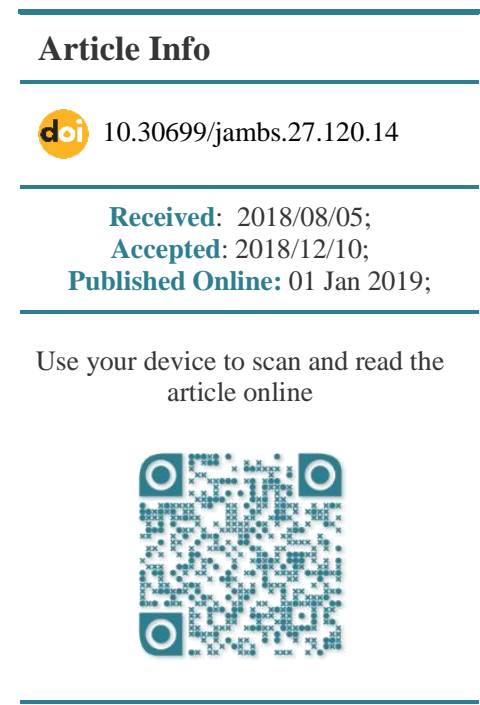

Corresponding Information:

Hamidreza Shetabi, Dept of

Anesthesiology, Faculty of

Medicine, Isfahan University of Medical

Sciences, Isfahan, Iran

Email: hamidshetabi@yahoo.com

\begin{abstract}
Background \& Objective: Several studies have shown that topical and intravenous Dexmedetomidine and Lidocaine can decrease pain and reduce consumption of analgesic drugs. However, Lidocaine may be accompanied with several side effects such as respiratory suppression, seizure, and cardiac arrhythmias. On the other hand, Dexmedetomidine has favorable properties such as low risk of apnea, analgesia, sympatholysis, and sedation. Therefore, the aim of this study was to compare the effects of nebulized Dexmedetomidine and nebulized Lidocaine on hemodynamic characteristics of the patients undergoing bronchoscopy.
\end{abstract}

Materials \& Methods: In the present randomized, double-blind study; 75 children (16 years old) undergoing fiber-optic bronchoscopy were allocated to three groups. Group 1 received nebulized solution containing $2 \mu \mathrm{g} / \mathrm{kg}$ of Dexmedetomidine. Group 2 received nebulized solution containing $4 \mathrm{mg} / \mathrm{kg}$ of Lidocaine $1 \%$. Group 3 received nebulized solution containing $0.9 \%$ of normal saline as the control group. Heart rate, mean arterial blood pressure and $\mathrm{SpO} 2$, Bispectral Index (BIS) were measured and compared. BIS, indicating the depth of anesthesia was considered as a confounding factor. Statistical analysis was performed using SPSS 20.

Results: The mean of arterial blood pressure and heart rate was significantly lower in group 1 compared to groups 2 and 3 during bronchoscopy $(P<0.05)$. Blood oxygen saturation and sedation scores were significantly higher in group 1 compared to the other groups during bronchoscopy $(P<0.05)$. Furthermore, the hemodynamic parameters were more stable in group 1 compared to the other groups during recovery.

Conclusion: Premedication with nebulized Dexmedetomidine was significantly associated with more stable hemodynamic parameters and lower risk of side effects compared to nebulized Lidocaine in children undergoing fiberoptic bronchoscopy.

Keywords: Bronchoscopy, Child, Dexmedetomidine, Lidocaine

\section{Introduction}

Fiber-optic bronchoscopy is a relatively safe method which is widely used nowadays for therapeutic and diagnostic aims (1). In children, bronchoscopy is a short but irritating process which would cause great challenges for managing anesthesia for the patients of this age group. One of the most important side effects of bronchoscopy is cerebral hypoxia which might be induced by various factors such as consumption of sedatives, partial obstruction of the airway, inappropriate ventilation and reflexive response to bronchoscopy and lavage (2). A patient's comfort is one of the most important factors for performing bronchoscopy, because the patient's cooperation would significantly lead to a comfortable bronchoscopy and achievement of therapeutic and diagnostic goals. Therefore, to increase a patients' tolerance and comfort, sedative drugs would be administered before bronchoscopy (3). Currently, no definitive recommendation has been made for the administration of sedative drugs for these patients but usually, a combination of short-acting benzodiazepines such as Midazolam and Propofol would be used (4). Also, to reduce the need for sedative drugs, local anesthesia of the airway was administered. So far, various anesthetic methods have been suggested for performing bronchoscopy, each associated with advantages and disadvantages. The anesthetic goals in children undergoing bronchoscopy include reducing the pressure by the patient, coughing during intubation, stabilizing patient's hemodynamic status and rapid recovery of the airway reflexes after the bronchoscopy (5). Persistent and long-lasting anesthesia after bronchoscopy could be associated with high levels of anesthetic agent in the body and an increased side effect as well as longer hospitalization (6). Various methods with controversial results have been suggested for anesthesia during bronchoscopy. Also new drugs and methods are under investigation, so that the anesthetic drugs and methods with most efficiency and least side effects would be 
administered especially in younger patients. As local anesthetics are rapidly absorbed into the blood flow through mucous membranes, they would increase the risk for systemic side effects (6). Local anesthetics such as Lidocaine Hydrochloride is usually used for reducing pain, decreasing the risk of Bradycardia, gag reflex and coughing. Lidocaine is usually administered by direct application through the bronchoscope, which might be associated with potentially toxic, high serum levels of Lidocaine (7). However, the substitute method for administration of Lidocaine is using nebulizer before performing the bronchoscopy. It has been shown that using nebulized Lidocaine is significantly effective in decreasing the serum levels of Lidocaine. Also using nebulized Lidocaine has similar effects as its injection (7). Although the prescription of Lidocaine is usually safe, sometimes it would lead to cardiac arrhythmias, seizure and in rare cases, cardiac arrest. The side effects of Lidocaine are more probable when its serum levels are higher than $5 \mathrm{mg} / \mathrm{L}$ or when it is accompanied with reduced liver function (8). Serious side effects require more attention in Lidocaine use. However, Dexmedetomidine is a selective agonist of alpha-twoadrenergic, which is increasingly being used in children. In comparison to other anesthetics, Dexmedetomidine has more favorable features which are not limited to its sedative, hemodynamic and anesthetic properties (9). Also, compared to other administered anesthetics before bronchoscopy, Dexmedetomidine would not suppress the respiratory system (10). The sedative effect of Dexmedetomidine, which is similar to the individual's natural sleep, has significantly increased its administration in children and in intensive care units. However, no studies have been conducted to evaluate the sedative effects of nebulized Dexmedetomidine and its effect on patients' hemodynamic status undergoing bronchoscopy. Therefore, the present study was conducted to compare the effect of premedication with nebulized Lidocaine and nebulized Dexmedetomidine on hemodynamic changes and respiratory complications in children undergoing fiber-optic bronchoscopy, and comparing their effects with a control group in Imam-Hussein hospital of Isfahan in 2016.

\section{Materials and Methods}

In the present randomized double-blind clinical trial, 75 children, who were hospitalized in Imam-Hussein hospital of Isfahan in 2016 were included. All enrolled children in the present study were 1 to 6 years old, undergoing fiber-optic bronchoscopy for diagnostic or therapeutic goals. The inclusion criteria were being 1 to 6 years old, being a candidate for fiber-optic bronchoscopy of ASA1 and ASA2 classes, and having consent for participation. The non-entry criteria were the ones who had any diagnosed cardiac or liver diseases, fever, crackle or bronchi when hearing the lungs, intubation, or were using other anesthetics or sedative drugs before the bronchoscopy. The exclusion criteria were lingered bronchoscopy beyond 30 minutes, and the occurrence of any complications that would lead to discontinuation of bronchoscopy. Before the study, all stages of the study and their probable complications were explained to all the patients and their parents, and they all provided written informed consent. The present study was approved by the ethics committee of Isfahan University of Medical Sciences (Ir.mui.rec.1395.3.505). For the executive stages of the study, necessary coordination was made with the management of Imam-Hussein hospital and the managers of the departments.

Sampling was conducted using simple sampling method. Patients were randomly allocated into three groups of 25 . The first group received premedication with $2 \mu \mathrm{g} / \mathrm{kg}$ of nebulized Dexmedetomidine, the second group received premedication with nebulized Lidocaine $1 \%(4 \mathrm{mg} / \mathrm{kg})$ and the third group received premedication with saline $0.9 \%$ as the control group, half an hour prior to the anesthesia. Then, after the injection of $0.1 \mathrm{mg} / \mathrm{kg}$ of Midazolam and $1 \mathrm{mg} / \mathrm{kg}$ of Ketamine, as premedication, the patients were transferred to the operating room to perform the fiber-optic bronchoscopy. Anesthesia was induced by injecting 2 $\mathrm{mg} / \mathrm{kg}$ of Atropine, $2 \mu \mathrm{g} / \mathrm{kg}$ of venous Fentanyl and 2 $\mathrm{mg} / \mathrm{kg}$ of Propofol. Anesthesia was maintained using 200 $\mu \mathrm{g} / \mathrm{kg} / \mathrm{min}$ of Propofol. Patients' anesthetic depth was evaluated during the bronchoscopy using a bispectral index. This was to make sure that the difference in the depth of anesthesia would not become a confounding factor for comparing the results of other factors, and that results would be similar in all groups. Heart rate, mean arterial blood pressure and blood oxygen saturation were recorded and compared between the three groups before prescribing the nebulizer, at the end of the nebulizer's prescription, during the bronchoscopy, and in the recovery room. The occurrence of tachycardia, which is defined as the heart rate $20 \%$ higher than the baseline heart rate, and bradycardia, which is defined as the heart rate $20 \%$ lower than the baseline heart rate, were recorded for all three groups. Also the occurrence of hypertension, as the mean of blood pressure $20 \%$ higher than the baseline mean of arterial pressure, and hypotension, as the mean of blood pressure $20 \%$ lower than the baseline mean arterial blood pressure, were recorded for all groups. The duration of recovery was recorded and compared between groups using Modified Aldrete Score. The level of satisfaction of the bronchoscopist during the bronchoscopy process was evaluated on a Likert scale of 1 to 5 and compared between the three groups. The level of sedation was recorded and compared between groups before the bronchoscopy, during the bronchoscopy, and at the arrival to the recovery room based on the Ramsay sedation scale.

Data were analyzed using SPSS 20 (SPSS Inc., Chicago, IL., USA). Kolmogorov-Smirnov Z-test was used to evaluate the normal distribution of the data and based on that, parametric or non-parametric tests were used for the analysis of quantitative data. To compare the quantitative variables between the three groups, one-way ANOVA and Kruskal-Wallis tests were used. To evaluate the relation between the quantitative variables Spearman and Pearson correlation coefficients were used. The distribution and relation between the qualitative variables was evaluated using Chi-square test. Data were presented as mean \pm 
standard deviation and number (percent); a P-value of less than 0.05 was considered as the significant level.

\section{Results}

In the present study, 75 children undergoing fiber-optic bronchoscopy were enrolled, and divided into three groups of 25. The mean age of the patients in the first group was $2.16 \pm 1.67$ years, in the second group $2.52 \pm 1.87$ years and in the third group $2.60 \pm 1.77$ years. No significant difference was observed between the three groups $(P=0.57)$. In all the three groups, 18 patients $(72 \%)$ were male, which was not statistically significant $(P>0.05)$. So, the patients in the present study were similar regarding their age and gender and no significant difference was observed between the groups regarding these variables. No significant difference was observed between the three groups regarding the heart rate before and after using the nebulizer $(P>0.05)$. A significant difference was observed between the three groups regarding heart rate at the beginning of the bronchoscopy and during the bronchoscopy; meaning that the heart rate in the third group was higher than the second group, and was higher in the second group compared to the first group $(P<0.05)$ (Table 1). No significant difference was observed between the three groups regarding the mean arterial blood pressure immediately after using the nebulizer, at the beginning of the bronchoscopy, and 5 minutes into the bronchoscopy $(P>0.05)$. However, the difference between the three groups regarding the mean arterial blood pressure before using the nebulizer, and 10, 15 and 20 minutes into the bronchoscopy was statistically significant. It was higher in the third group compared to the second group and higher in the second group compared to the first group $(P<0.05)$. Regarding the mean of blood oxygen saturation, no significant difference was observed between the three groups before using the nebulizer, immediately after using the nebulizer, at the beginning of the bronchoscopy and 5 minutes into the bronchoscopy $(P>0.05)$. However, this difference was significant between the groups during the bronchoscopy $(P<0.05)$. Other information about the effect nebulizer in the three studied groups on patients' hemodynamic and anesthetic factors is shown in Table 1. A significant difference was observed between the three groups regarding the level of satisfaction of the bronchoscopist while performing the fiber-optic bronchoscopy; this level was higher in the first group $(4.92 \pm 0.27)$ than in the second group $(4.16 \pm 0.62)$ and was also higher in the second group than in the third group $(3.68 \pm 0.62)$ $(P<0.01)$. Recording the vital signs of the patients in recovery showed a significant difference between the three groups regarding their mean heart rate at the time of arrival to the recovery and while being in the recovery; the mean was higher in the third group compared to the second group and higher in the second group compared to the third group $(P<0.05)$. Results about the mean arterial blood pressure and the mean of blood oxygen saturation of the patients in the three groups at the time of arrival to the recovery and while being in the recovery also showed a similar significant difference $(P<0.01)$ (Table 2$)$. No complications were observed in the patients of the first group; however, in the patients of the second group, complications such as tachycardia (12\%), hypertension $(8 \%)$, decreased blood oxygen saturation $(4 \%)$, and laryngospasm (4\%) were observed. Also in the patients of the third group, complications such as bronchospasm $(8 \%)$, repeated coughing $(8 \%)$, laryngospasm $(8 \%)$, tachycardia $(12 \%)$, hypertension $(12 \%)$ and decreased blood oxygen saturation $(32 \%)$ were found.

Table 1. The effect of nebulized Dexmedetomidine, nebulized Lidocaine and normal saline on hemodynamic and anesthetic factors before using the nebulizer, after using the nebulizer and during the bronchoscopy

\begin{tabular}{|c|c|c|c|c|c|c|c|c|}
\hline \multicolumn{2}{|c|}{$\begin{array}{l}\text { Hemodynamic and } \\
\text { anesthetic factors }\end{array}$} & $\begin{array}{l}\text { Before using } \\
\text { nebulizer }\end{array}$ & $\begin{array}{l}\text { After using } \\
\text { nebulizer }\end{array}$ & $\begin{array}{l}\text { Beginning of } \\
\text { bronchoscopy }\end{array}$ & $\begin{array}{l}5 \text { minutes into } \\
\text { bronchoscopy }\end{array}$ & $\begin{array}{l}10 \text { minutes } \\
\text { into } \\
\text { bronchoscopy }\end{array}$ & $\begin{array}{l}15 \text { minutes } \\
\text { into } \\
\text { bronchoscopy }\end{array}$ & $\begin{array}{l}20 \text { minutes } \\
\text { into } \\
\text { bronchoscopy }\end{array}$ \\
\hline \multirow{3}{*}{$\begin{array}{l}\text { Heart } \\
\text { rate }\end{array}$} & $\begin{array}{l}\text { First } \\
\text { group }\end{array}$ & $130.76 \pm 7.25$ & $124.64 \pm 6.40$ & $122.56 \pm 6.21$ & $120.76 \pm 6.59$ & $119.36 \pm 7$ & $118.46 \pm 7.01$ & $117.48 \pm 7.22$ \\
\hline & $\begin{array}{l}\text { Second } \\
\text { group }\end{array}$ & $127.95 \pm 6.57$ & $126.86 \pm 6.26$ & $125.52 \pm 5.46$ & $128.34 \pm 8.32$ & $130.60 \pm 9.95$ & $129.82 \pm 11.01$ & $130.17 \pm 11.13$ \\
\hline & $\begin{array}{l}\text { Third } \\
\text { group }\end{array}$ & $126.96 \pm 5.36$ & $126.44 \pm 4.80$ & $129.08 \pm 7.96$ & $132.32 \pm 8.20$ & $133.24 \pm 8.82$ & $134.1 \pm 8.70$ & $133.92 \pm 8.25$ \\
\hline \multicolumn{2}{|c|}{ P-value } & 0.12 & 0.32 & 0.04 & $<0.01$ & $<0.01$ & $<0.01$ & $<0.01$ \\
\hline \multirow{3}{*}{$\begin{array}{c}\text { Mean } \\
\text { arterial } \\
\text { blood } \\
\text { pressure }\end{array}$} & $\begin{array}{l}\text { First } \\
\text { group }\end{array}$ & $65.68 \pm 10.85$ & $60.16 \pm 4.27$ & $59.64 \pm 3.95$ & $59.12 \pm 3.71$ & $58.48 \pm 3.50$ & $57.88 \pm 3.43$ & $57.84 \pm 3.35$ \\
\hline & $\begin{array}{l}\text { Second } \\
\text { group }\end{array}$ & $61.91 \pm 5.60$ & $61.21 \pm 5.60$ & $61.52 \pm 5.03$ & $60.86 \pm 5.84$ & $62.73 \pm 5.28$ & $62.82 \pm 5.33$ & $63.34 \pm 5.49$ \\
\hline & $\begin{array}{l}\text { Third } \\
\text { group }\end{array}$ & $60.56 \pm 4.77$ & $60.44 \pm 4.47$ & $61.44 \pm 4.98$ & $60.76 \pm 5.30$ & $64.24 \pm 5.69$ & $64.20 \pm 5.57$ & $64.08 \pm 5.61$ \\
\hline \multicolumn{2}{|c|}{ P-value } & 0.04 & 0.88 & 0.36 & 0.06 & $<0.01$ & $<0.01$ & $<0.01$ \\
\hline \multirow{3}{*}{$\begin{array}{c}\text { Blood } \\
\text { oxygen } \\
\text { saturation }\end{array}$} & $\begin{array}{l}\text { First } \\
\text { group }\end{array}$ & $97.16 \pm 2.23$ & $97.24 \pm 2.08$ & $97.28 \pm 2.18$ & $97.16 \pm 2.46$ & $97.12 \pm 2.57$ & $97.20 \pm 2.72$ & $97.32 \pm 2.54$ \\
\hline & $\begin{array}{l}\text { Second } \\
\text { group }\end{array}$ & $97.56 \pm 1.64$ & $97.73 \pm 1.68$ & $97.73 \pm 1.68$ & $97.34 \pm 2.18$ & $97.26 \pm 2.52$ & $97.21 \pm 2.96$ & $97.17 \pm 3$ \\
\hline & $\begin{array}{l}\text { Third } \\
\text { group }\end{array}$ & $97.04 \pm 1.74$ & $97.20 \pm 1.65$ & $96.48 \pm 3.70$ & $94.64 \pm 5.31$ & $93.32 \pm 6.56$ & $92.72 \pm 6.99$ & $93.12 \pm 6.57$ \\
\hline \multicolumn{2}{|c|}{ P-value } & 0.55 & 0.46 & 0.39 & 0.07 & 0.04 & 0.01 & 0.04 \\
\hline
\end{tabular}




\begin{tabular}{|c|c|c|c|c|c|c|c|c|}
\hline \multicolumn{2}{|c|}{$\begin{array}{l}\text { Hemodynamic and } \\
\text { anesthetic factors }\end{array}$} & $\begin{array}{l}\text { Before using } \\
\text { nebulizer }\end{array}$ & $\begin{array}{l}\text { After using } \\
\text { nebulizer }\end{array}$ & $\begin{array}{l}\text { Beginning of } \\
\text { bronchoscopy }\end{array}$ & $\begin{array}{l}5 \text { minutes into } \\
\text { bronchoscopy }\end{array}$ & $\begin{array}{l}10 \text { minutes } \\
\text { into } \\
\text { bronchoscopy }\end{array}$ & $\begin{array}{l}15 \text { minutes } \\
\text { into } \\
\text { bronchoscopy }\end{array}$ & $\begin{array}{l}20 \text { minutes } \\
\text { into } \\
\text { bronchoscopy }\end{array}$ \\
\hline \multirow{3}{*}{$\begin{array}{l}\text { Sedation } \\
\text { score }\end{array}$} & $\begin{array}{l}\text { First } \\
\text { group }\end{array}$ & $1.94 \pm 0.22$ & $2.12 \pm 0.60$ & $5.16 \pm 0.62$ & $5.20 \pm 0.40$ & $5.20 \pm 0.40$ & $5.24 \pm 0.43$ & $5 \pm 0.50$ \\
\hline & $\begin{array}{l}\text { Second } \\
\text { group }\end{array}$ & $1.92 \pm 0.27$ & $1.91 \pm 0.28$ & $5.08 \pm 0.51$ & $5.04 \pm 0.63$ & $4.69 \pm 0.63$ & $4.60 \pm 0.65$ & $4.56 \pm 0.58$ \\
\hline & $\begin{array}{l}\text { Third } \\
\text { group }\end{array}$ & $1.94 \pm 0.22$ & $1.92 \pm 0.27$ & $4.76 \pm 0.72$ & $4.48 \pm 0.65$ & $4.36 \pm 0.86$ & $4.40 \pm 0.91$ & $4.40 \pm 0.86$ \\
\hline \multicolumn{2}{|c|}{ P-value } & 0.35 & 0.11 & 0.08 & $<0.01$ & $<0.01$ & $<0.01$ & 0.01 \\
\hline \multirow{3}{*}{$\begin{array}{l}\text { Bispectra } \\
1 \text { index }\end{array}$} & $\begin{array}{l}\text { First } \\
\text { group }\end{array}$ & 100 & 100 & $64.84 \pm 6.29$ & $63.72 \pm 4.75$ & $63.16 \pm 4.88$ & $62.32 \pm 4.63$ & $62.84 \pm 3.88$ \\
\hline & $\begin{array}{l}\text { Second } \\
\text { group }\end{array}$ & 100 & 100 & $68.08 \pm 4.85$ & $67.39 \pm 4.96$ & $68.21 \pm 4.49$ & $68.91 \pm 3.82$ & $69.65 \pm 3.51$ \\
\hline & $\begin{array}{l}\text { Third } \\
\text { group }\end{array}$ & 100 & 100 & $66.96 \pm 3.84$ & $67.96 \pm 3.71$ & $68.72 \pm 4.18$ & $68.84 \pm 4.67$ & $68.72 \pm 5.13$ \\
\hline \multicolumn{2}{|c|}{ P-value } & - & - & 0.22 & 0.91 & 0.40 & 0.71 & 0.52 \\
\hline
\end{tabular}

Table 2. The effect of nebulized Dexmedetomidine, nebulized Lidocaine and normal saline on hemodynamic and anesthetic factors after performing the fiberoptic bronchoscopy at different times in the recovery

\begin{tabular}{|c|c|c|c|c|c|c|}
\hline \multicolumn{2}{|c|}{ Hemodynamic and anesthetic factors } & $\begin{array}{l}\text { Arrival at the } \\
\text { recovery }\end{array}$ & $\begin{array}{l}15 \text { minutes into } \\
\text { the recovery }\end{array}$ & $\begin{array}{l}30 \text { minutes into } \\
\text { the recovery }\end{array}$ & $\begin{array}{l}45 \text { minutes into } \\
\text { the recovery }\end{array}$ & $\begin{array}{l}60 \text { minutes into the } \\
\text { recovery }\end{array}$ \\
\hline \multirow{3}{*}{ Heart rate } & First group & $115.48 \pm 8.15$ & $115.60 \pm 7.75$ & $117.36 \pm 8.61$ & $115.12 \pm 7.36$ & $115.08 \pm 7.91$ \\
\hline & Second group & $126.60 \pm 9.50$ & $125.68 \pm 9.02$ & $124.57 \pm 7.86$ & $124.36 \pm 8.68$ & $125.40 \pm 8.37$ \\
\hline & Third group & $128.28 \pm 6.85$ & $127.36 \pm 5.57$ & $126.72 \pm 5.69$ & $126.08 \pm 4.48$ & $125.16 \pm 4.66$ \\
\hline \multicolumn{2}{|c|}{ P-value } & $<0.01$ & $<0.01$ & $<0.01$ & $<0.01$ & $<0.01$ \\
\hline \multirow{3}{*}{$\begin{array}{c}\text { Mean arterial blood } \\
\text { pressure }\end{array}$} & First group & $57.12 \pm 3.17$ & $56.68 \pm 3.21$ & $54.52 \pm 10.75$ & $56.36 \pm 3.28$ & $54.40 \pm 10.79$ \\
\hline & Second group & $61.24 \pm 4.37$ & $60.64 \pm 4.41$ & $60.48 \pm 4.50$ & $60.84 \pm 4.33$ & $60.44 \pm 4.47$ \\
\hline & Third group & $63.68 \pm 8.21$ & $62.92 \pm 7.72$ & $62.92 \pm 7.95$ & $62.72 \pm 8.04$ & $62.40 \pm 7.91$ \\
\hline \multicolumn{2}{|c|}{ P-value } & $<0.01$ & $<0.01$ & $<0.01$ & $<0.01$ & $<0.01$ \\
\hline \multirow{3}{*}{$\begin{array}{l}\text { Blood oxygen } \\
\text { saturation }\end{array}$} & First group & $98.40 \pm 1.25$ & $98.56 \pm 1.22$ & $98.72 \pm 1.06$ & $98.56 \pm 1.26$ & $98.60 \pm 1.25$ \\
\hline & Second group & $98 \pm 1.58$ & $97.92 \pm 1.65$ & $98.12 \pm 1.66$ & $98.04 \pm 2$ & $98 \pm 1.44$ \\
\hline & Third group & $96.52 \pm 2.43$ & $96.64 \pm 2.36$ & $96.96 \pm 2.20$ & $97.08 \pm 2.17$ & $97.20 \pm 1.93$ \\
\hline \multicolumn{2}{|c|}{ P-value } & 0.04 & 0.04 & 0.04 & 0.03 & 0.02 \\
\hline \multirow{3}{*}{ Sedation score } & First group & $3.64 \pm 0.7$ & $2.36 \pm 0.70$ & $2.20 \pm 0.64$ & $2.16 \pm 0.62$ & $2.20 \pm 0.64$ \\
\hline & Second group & $3.41 \pm 0.65$ & $2.45 \pm 0.58$ & $2.12 \pm 0.33$ & $1.95 \pm 0.20$ & $2.12 \pm 0.33$ \\
\hline & Third group & $3.56 \pm 0.50$ & $2.88 \pm 0.78$ & $2.16 \pm 0.47$ & $1.96 \pm 0.20$ & $2.08 \pm 0.27$ \\
\hline \multicolumn{2}{|c|}{$\mathrm{P}$-value } & 0.64 & 0.01 & 0.93 & 0.11 & 0.69 \\
\hline
\end{tabular}

\section{Discussion}

For the first time, the present study compared the effect of premedication with nebulized Lidocaine and nebulized Dexmedetomidine on hemodynamic changes and respiratory complications in children undergoing fiberoptic bronchoscopy. Results of the present study showed that using nebulized Dexmedetomidine led to a significantly lower heart rate at the beginning of the bronchoscopy and during the procedure compared to nebulized Lidocaine and saline. Similarly, using nebulized Dexmedetomidine caused a lower mean arterial blood pressure during the bronchoscopy in comparison with nebulized Lidocaine and saline. Nebulized Dexmedetomidine caused higher level of blood oxygen saturation compared to nebulized Lidocaine; which probably was due to the suppressive effect of Lidocaine on the respiratory system in comparison with Dexmedetomidine. Regarding the score of sedation, also, the group that received nebulized Dexmedetomidine had higher levels of sedation compared to the groups that received nebulized Lidocaine and saline. On the other hand, the bispectral index, which shows the depth of anesthesia and could act as a confounding factor, showed 
no significant difference between the three groups and at different times of measurement. Evaluating the mentioned hemodynamic and anesthetic factors at the time of arrival to the recovery and at different measurement times during the stay in the recovery, showed similar results as the results during the bronchoscopy. Regarding the studied complications in the present study, using nebulized Dexmedetomidine resulted in fewer hemodynamic and respiratory complications compared to nebulized Lidocaine. Although various guidelines have suggested the use of Lidocaine during the procedure of bronchoscopy to reduce cough and pain, there are still concerns about the side effects of Lidocaine such as seizure, exacerbation of infectious diseases of the respiratory system, suppression of the respiratory system and decrease in the level of blood oxygen saturation (11). No cases of seizure happened in the present study. In general, complications were higher in the group receiving Lidocaine compared to the Dexmedetomidine and the saline group; Lidocaine use and dosage require more careful attention in patients undergoing bronchoscopy. $\mathrm{Xu}$ et al. conducted a study to compare the effect of intravenous injection of Lidocaine, Dexmedetomidine, and the combination of the two agents on pain relief after surgery and the need for anesthetic drugs (12). In their study, 240 patients were allocated into four groups of receiving normal saline (as the control), receiving Lidocaine, receiving Dexmedetomidine, and receiving Lidocaine and Dexmedetomidine simultaneously. Results of the study showed that using the injectable form of Lidocaine along with Dexmedetomidine in comparison with the other three groups and also injecting Dexmedetomidine in comparison with Lidocaine had significantly higher effects on patients' pain relief and the decrease in the need for anesthetic drugs. However, there are fundamental difference between the present study and the study of $\mathrm{Xu}$ et al.; they used the injectable form of Lidocaine and Dexmedetomidine, and also their sample size was larger than the sample size of the present study. Besides comparing the effect of Lidocaine to Dexmedetomidine, this drug has also been compared to Midazolam, which is one of the most important sedative drugs for performing bronchoscopy. In this regard, Liao et al. conducted a study to compare the effect of infusion of Midazolam with Dexmedetomidine on the hemodynamic factors of patients undergoing bronchoscopy (13). Results of their study showed that using Dexmedetomidine had sedative effects similar to Midazolam, however with less respiratory complications and higher levels of blood oxygen saturation. Also, similar to the results of the present study, the group that received Dexmedetomidine had lower levels of arterial blood pressure and heart rate. However, their study also had a major difference with the present study in using the injectable form of Dexmedetomidine instead of its nebulized form. Although, so far, no studies have been performed to compare the effect of nebulized Dexmedetomidine and nebulized Lidocaine, studies that have compared the topical or injectable forms of these two drugs have shown that simultaneous use of these two drugs had more effect in pain relief and increasing anesthesia compared to using each one alone $(12,14,15)$.

Limitation: One of the limitations of the present study was lack of evaluating the effect of simultaneous nebulized Dexmedetomidine and Lidocaine on patients undergoing bronchoscopy. Also, another limitation of the present study was the lack of comparison between topical and injectable forms of Dexmedetomidine and Lidocaine with their nebulized forms. Therefore, it is recommended that future studies be conducted with larger sample sizes to evaluate the efficacy of nebulized Dexmedetomidine compared to its topical and injectable forms and also topical and injectable forms of Lidocaine on patients undergoing bronchoscopy.

\section{Conclusion}

In conclusion, results of the present study showed that using nebulized Dexmedetomidine, in comparison with using nebulized Lidocaine, had better effects on the sedation level, and hemodynamic and anesthetic factors of children undergoing bronchoscopy. Also using nebulized Dexmedetomidine is associated with fewer respiratory and hemodynamic complications in comparison with nebulized Lidocaine. However, performing further studies with larger sample sizes to compare the effect of different doses and forms of Dexmedetomidine on children undergoing bronchoscopy is recommended to approve the results of the present study.

\section{Acknowledgements}

The authors thank all those who helped them writing this paper.

\section{Conflict of Interest}

Authors declared no conflict of interests.

\section{References}

1. Karišik M, Janjević D, Sorbello M. Fiberoptic bronchoscopy versus video laryngoscopy in pediatric airway management. Acta Clinica Croatica. 2016; 55: 51-4. [DOI:10.20471/ acc.2016.55.s1.06]

2. Chen SJ, Tang RB. Risk factors of hypoxia during flexible bronchoscopy use in infants. J Chinese Med Assoc. 2012; 75: 95 96. [DOI:10.1016/i.jc ma.2011.12.010] [PMID]

3. Kern M, Kerner T, Tank S. Sedation for advanced procedures in the bronchoscopy suite: proceduralist or anesthesiologist? Curr

Journal of Advances in Medical and Biomedical Research 
Opin Anesthesiol. 2017; 30: 490-95. [DOI:10.1097/ACO. 0000000000000483] [PMID]

4. Lin TY, Lo YL, Hsieh CH, et al. The potential regimen of targetcontrolled infusion of propofol in flexible bronchoscopy sedation: a randomized controlled trial. PloS one. 2013; 8: e62744. [DOI:10.1371/journal.pone.0062744] [PMID] [PMCID]

5. Chadha M, Kulshrestha M, Biyani A. Anaesthesia for bronchoscopy. Indian J Anaesth. 2015; 59: 565-73. [DOI:10.4103/0019-5049.165851] [PMID] [PMCID]

6. Martin LD, Jimenez N, Lynn AM. A review of perioperative anesthesia and analgesia for infants: updates and trends to watch. F1000Res. 2017; 6: 120. [DOI:10.12688/f1000research. 10272.1] [PMID] [PMCID]

7. Gjonaj ST, Lowenthal DB, Dozor AJ. Nebulized lidocaine administered to infants and children undergoing flexible bronchoscopy. Chest. 1997; 112: 1665-9. [DOI:10.1378/chest. 112.6.1665] [PMID]

8. Tran AN, Koo JY. Risk of systemic toxicity with topical lidocaine/prilocaine: a review. Journal of drugs in dermatology:

9. Davoudi A, Movahedian Attar B, Shadmehr E. Risks and benefits of pre-operative dexmedetomidine in oral and maxillofacial surgeries: A systematic review. Expert Opin Drug Safe. 2017; 16: 711-720. [DOI:10.1080/14740338. 2017.1323865] [PMID]
10. Cozzi G, Norbedo S, Barbi E. Intranasal dexmedetomidine for procedural sedation in children, a suitable alternative to chloral hydrate. Pediatr Drug. 2017; 19: 107-11. [DOI:10.1007/s40272017-0217-5] [PMID]

11. Daykin H. The efficacy and safety of intravenous lidocaine for analgesia in the older adult: a literature review. Br J pain. 2017; 11: 23-31. [DOI:10.1177/2049463716676205] [PMID] [PMCID]

12. Xu S, Li Y, Wang S, Hu S, Ju X, Xiao J. Effects of intravenous lidocaine, dexmedetomidine and their combination on the postoperative pain and recovery of bowel function in patients undergoing abdominal hysterectomy. Minerva Anestesiologica. 2017; 83: 685-94.

13. Liao W, Ma G, Su Q, Fang Y, Gu B, Zou X. Dexmedetomidine versus midazolam for conscious sedation in postoperative patients undergoing flexible bronchoscopy: a randomized study. J Int Med Res. 2012; 40: 1371-80. [DOI:10.1177/14732300 1204000415] [PMID]

14. Hu X, Li J, Zhou R, et al. Dexmedetomidine added to local anesthetic mixture of lidocaine and ropivacaine enhances onset and prolongs duration of a popliteal approach to sciatic nerve blockade. Clin Ther. 2017; 39: 89-97. [DOI:10.1016/j.clinther a.2016.11.011] [PMID]

15. Ouchi K, Sugiyama K. Dexmedetomidine dose dependently enhances the local anesthetic action of lidocaine in inferior alveolar nerve block: a randomized double-blind study. Reg Anesth Pain Med. 2016; 41: 348-55. [DOI:10.1097/AA P.0000000000000380] [PMID]

\section{How to Cite This Article:}

Shafa A, Habibzade M, Shetabi H, Agil A. Comparing the Hemodynamic Effects of Nebulized Dexmedetomidine and Nebulized Lidocaine in Children undergoing Fiberoptic Bronchoscopy. J Adv Med Biomed Res. 2019; 27 (120) :14-19

\section{Download citation:}

BibTeX | RIS | EndNote | Medlars | ProCite| Reference Manager | RefWorks

\section{Send citation to:}
Mendeley 